\section{Prolegómenos}

Derecho y Valores
Prolegómenos. Derechos y Valores

ISSN: 0121-182X

derechos.valores@umng.edu.co

Universidad Militar Nueva Granada

Colombia

Mejía Ossman, Jaime

INTERVENCIÓN DE LOS ESTUDIANTES DE LOS CONSULTORIOS JURÍDICOS COMO

DEFENSORES DE OFICIO EN LOS PROCESOS DISCIPLINARIOS

Prolegómenos. Derechos y Valores, vol. XV, núm. 29, enero-junio, 2012, pp. 21-34

Universidad Militar Nueva Granada

Bogotá, Colombia

Disponible en: http://www.redalyc.org/articulo.oa?id=87625419002

- Cómo citar el artículo

- Número completo

- Más información del artículo

Página de la revista en redalyc.org

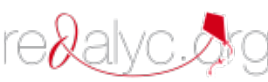

Sistema de Información Científica

Red de Revistas Científicas de América Latina, el Caribe, España y Portugal

Proyecto académico sin fines de lucro, desarrollado bajo la iniciativa de acceso abierto 


\title{
INTERVENCIÓN DE LOS ESTUDIANTES DE LOS CONSULTORIOS JURÍDICOS* COMO DEFENSORES DE OFICIO EN LOS PROCESOS DISCIPLINARIOS**
}

Jaime Mejía Ossman ${ }^{* * *}$

Fecha de Recibido: 15 de Septiembre de 2011

Fecha de Aprobación: 7 de Noviembre de 2011.

Artículo resultado de proyecto de Investigación.

\begin{abstract}
Resumen
Con el presente trabajo se pretende justificar jurídicamente la viabilidad de que los estudiantes de los Consultorios Jurídicos de las universidades reconocidas legalmente, puedan sin afectación a las garantías fundamentales de los investigados, desempeñarse como defensores de oficio en los casos expresamente establecidos en la Ley 734 de febrero 5 de 2002 o Código Disciplinario Único y en las demás codificaciones disciplinarias.
\end{abstract}

\section{Palabras clave}

Derecho a la defensa técnica, código disciplinario único, estudiantes de clínicas jurídicas, defensores del procedimiento disciplinario, defensores de oficio, derechos fundamentales, debido proceso, adecuación, control y seguimiento.

* De las Universidades reconocidas legalmente. Artículo 17 Ley 734 de febrero 5 de 2002. MEJÍA OSSMAN, Jaime. Régimen Disciplinario. Bogotá: Doctrina y Ley, 2007. 2007. p 33.

** Este trabajo es parte del resultado de una investigación realizada para optar al título de Maestría en Derecho Público Militar en la Universidad Militar Nueva Granada, promoción 2010.

*** Especialista en Derecho Disciplinario, Especializado en Derecho Penal, Criminología, Criminalística y Derecho Probatorio; con Maestría en Derecho Público Militar y Candidato a Doctor en Derecho, Abogado Litigante en Derecho Penal y Derecho Disciplinario, Consultor en aspectos de reforma de la justicia y del menor infractor del Banco Interamericano de Desarrollo (BID), Conferencista en Derecho Sancionatorio, Miembro Honorario del Colegio de Expertos en Derecho Disciplinario, Director y profesor de la Especialización en Derecho Sancionatorio de la Universidad Militar Nueva Granada, Coordinador del Comité Jurídico Nacional de la Fuerza Aérea Colombiana, Miembro de la Mesa para el Acompañamiento de la Reforma de la Justicia Penal Militar hasta el año 2009, Director del Equipo para la Reforma del Reglamento del Régimen Disciplinario para las Fuerzas Militares de Colombia, Coautor de los Módulos en Derecho Internacional Humanitario Vs Falta Disciplinaria y Tratamiento de los Principios del Derecho Internacional Humanitario con relación a las faltas descritas en el Código Disciplinario Único (Vicepresidencia de la República), Autor de más de 18 Obras en Derecho Disciplinario, Presidente del Colegio de Abogados en Derecho Disciplinario, Conjuez del Tribunal Superior de Bogotá (Sala Penal) desde 1998 hasta el año 2008, Conjuez del Consejo Superior de la Judicatura (Sala Disciplinaria) hasta el año 2009, Veedor Nacional del Partido Conservador Colombiano, Teniente Coronel de los Profesionales Oficiales de la Reserva de la Fuerza Aérea Colombiana, profesor de la Escuela Superior de Guerra y de la Escuela de Derechos Humanos y de Derecho Internacional Humanitario del Ejército Nacional de Colombia. correos electrónicos: mejiaossman@cable.net.co jaimemejiaossman@hotmail.com 


\title{
INTERVENTION OF STUDENTS OF CLINICS LEGAL AS DEFENDERS OF EX OFFICIO IN THE DISCIPLINARY PROCEEDINGS
}

\begin{abstract}
Abstrac
The present paper is intended to legally justify the feasibility that the students of the legal clinics of the Universities recognized legally, can without affectation to the fundamental guaranties of the investigated, play as defenders of ex officio in cases expressly provide for in the 734 law of February 5 of 2002, or single disciplinary code and the other disciplinary codes.
\end{abstract}

\section{Key Words}

Right to technical defence, single disciplinary code, students of legal clinics, defenders of ex officio, disciplinary proceedings, fundamental rights, due process, suitability, control and monitoring.

\section{INTERVENÇÃO DOS ALUNOS DE CLÍNICAS LEGAIS COMO DEFENSORES DE OFÍCIO NO PROCESSO DISCIPLINAR}

\begin{abstract}
Resumo
O presente documento destina-se a legalmente justificar a viabilidade que os estudantes das clínicas legais das universidades reconhecidas legalmente, pode sem afectação às garantias fundamentais do objecto do inquérito, jogar como defensores da ex officio nos casos expressamente previstos na lei 734 de 5 de fevereiro de 2002 ou único código disciplinar e outros códigos disciplinares.
\end{abstract}

\section{Palavras-chave}

Direito à defesa técnica, único código disciplinar, estudantes de clínicas legais, defensores do processo disciplinar, oficiosamente, direitos fundamentais, do devido processo, adequação, controlo e vigilância.

\section{INTRODUCCIÓN}

El derecho a la defensa técnica, en materia disciplinaria, encuentra respaldo en el artículo 29 de la Constitución Política y en los artículos 17 y 93 de la Ley 734 de febrero 5 de 2002 o Código Disciplinario Único.

Con ocasión a lo expresado en la jurisprudencia, la Corte Constitucional ha aceptado la participación de los estudiantes de los Consultorios Jurídicos en los procesos disciplinarios como defensores de oficio, con respaldo en las Leyes 600 de julio 24 de 2000 y Decreto 196 de febrero 12 de 1971, amén de lo contemplado en la Ley Estatutaria de la Administración de Justicia: L. 270 del 7 de marzo de 1996.

Hoy, al quedar derogadas las leyes 600 de 2000 y el Decreto 196 de 1971, desaparece el fundamento legal general que permitía interpretar y aplicar la figura del defensor de oficio en cabeza de los estudiantes de los Consultorios Jurídicos, dentro del proceso disciplinario. 
Para suplir esta deficiencia normativa, por integración dispositiva, prevista en el artículo 21 de la Ley 734 de febrero 5 de 2002, habrá de remitirse a las orientaciones rectoras constitucionales, las cuales a su vez permiten aplicar la Ley 270 de marzo 7 de 1996 (Ley Estatutaria de la Administración de Justicia) ${ }^{1}$, toda vez que por resolución del jefe máximo del Ministerio Público, en la que se dijo que la nueva codificación procedimental penal (Ley 906 de agosto 31 de 2004), es contraria a la naturaleza del Código Disciplinario Único y

1 Además, recuérdese que los artículos $8^{\circ}$ y 48 de la Ley 153 de agosto 15 de 1887 señalan:

"Artículo $8^{\circ}$. Cuando no hay ley exactamente aplicable al caso controvertido, se aplicarán las leyes que regulen casos ó materias semejantes, y en su defecto, la doctrina constitucional y las reglas generales de derecho".

Artículo 48. Los jueces ó magistrados que rehusaren juzgar pretextando silencio, oscuridad ó insuficiencia de la ley, incurrirán en responsabilidad por denegación de justicia. Y las anteriores concreciones normativas son pertinentes, por considerar la Ley Estatutaria de la Administración de Justicia en su preámbulo "que la justicia es un valor superior consagrado en la Constitución Política que debe guiar la acción del Estado y está llamada a garantizar la efectividad de los derechos fundamentales, dentro del marco del Estado Social y Democrático de Derecho, y a lograr la convivencia pacífica entre los colombianos, y que dada la trascendencia de su misión debe generar responsabilidad de quienes están encargados de ejercerla". Igualmente, la Ley Estatutaria de la Administración de Justicia, en el Título I (Principios de la Administración de Justicia), artículos $1^{\circ}, 2^{\circ}$ y $3^{\circ}$, en su orden, expresan: Artículo $1^{\circ}$. Administración de justicia. La administración de justicia es la parte de la función pública que cumple el Estado encargada por la Constitución Política y la ley de hacer efectivos los derechos, obligaciones, garantías y libertades consagrados en ellas, con el fin de realizar la convivencia social y lograr y mantener la concordia nacional.

Artículo $2^{\circ}$. Acceso a la justicia. El Estado garantiza el acceso de todos los asociados a la administración de justicia. Será de su cargo el amparo de pobreza y el servicio de defensoría pública. En cada municipio habrá como mínimo un defensor público.

Artículo $3^{\circ}$. Derecho de defensa. En toda clase de actuaciones judiciales y administrativas se garantiza, sin excepción alguna, el derecho de defensa, de acuerdo con la Constitución Política, los tratados internacionales vigentes ratificados por Colombia y la ley. Los estudiantes de derecho pertenecientes a los consultorios jurídicos de las universidades debidamente reconocidas por el Estado podrán ejercer la defensa técnica con las limitaciones que señale la ley, siempre y cuando la universidad certifique que son idóneos para ejercerla. no regula la institución del "defensor de oficio" (Arboleda, 2008) ${ }^{2}$, razones por la cuales deviene su inaplicación dentro del proceso disciplinario. Será entonces objeto de este trabajo el concretar la posibilidad y pertinencia para que los estudiantes de los Consultorios Jurídicos puedan actuar como defensores de oficio, siempre y cuando se encuentren bajo el "control" y "supervisión" de la universidad respectiva ${ }^{3}$ y se constate su "idoneidad" profesional y personal ${ }^{4}$.

2 Allí se habla de "defensoría Pública". Ver artículos 118, 122 (2), 127, 289, 291, 303 (4), 337 (3) y 529 (4) de la Ley 906 de agosto 31 de 2004 o Código de Procedimiento Penal. ARBOLEDA VALLEJO, Mario. Código Penal y de Procedimiento Penal Anotado. Vigesimacuarta edición. Bogotá D.C.: Leyer, 2008.

3 En demanda que presentara Carlos Mario Isaza Serrano, la Corte Constitucional en Sentencia C-1076 de diciembre 5 de 2002, con ponencia de Clara Inés Vargas Hernández, citando varias sentencias de constitucionalidad, entre ellas: C-049 de 1996 de Fabio Morón Díaz; C-143 de febrero 7 de 2001 de José Gregorio Hernández Galindo y C-040 de enero 28 de 2003 de Clara Inés Vargas Hernández, expresó:

"[...] la ley pueda habilitar defensores que reúnan al menos las condiciones de egresados o de estudiantes de derecho pertenecientes a un consultorio jurídico, desde luego, garantizando un mínimo de formación e idoneidad técnica y profesional para que pueda atender a las necesidades profesionales del defendido. Se trata simplemente de permitir que personas calificadas por sus estudios profesionales, bajo la coordinación científica y académica de los consultorios jurídicos de las universidades con facultades de derecho y egresados de las mismas, en trance de obtención del título profesional o del cumplimiento de requisitos especiales para el mismo como el de la judicatura, pongan sus conocimientos profesionales adquiridos $y$ actúen como abogados en la defensa de los intereses de los sindicados en los procesos penales, durante las etapas de investigación y juzgamiento [...]”.

4 De acuerdo con el precedente constitucional, la Corte en Sentencia C-948 de noviembre 6 de 2002, con ponencia de Álvaro Tafur Galvis, dijo:

"[...] la certificación de idoneidad que las universidades deban otorgar a los estudiantes de derecho de los consultorios jurídicos para ejercer la defensa técnica, no puede de ningún modo circunscribirse exclusivamente a la valoración académica de la persona, sino que debe incluir el comportamiento moral y ético que el estudiante ha demostrado a lo largo de sus carrera universitaria. Lo anterior porque, de una parte, la jurisprudencia de esta Corte ha sido clara en resaltar que quien asista a una persona en su defensa judicial debe 
En síntesis, con este artículo, se pretende clarificar los mecanismos expeditos para permitir la participación de los referidos estudiantes en las investigaciones disciplinarias, sin que se conculquen las garantías fundamentales de los destinatarios de la ley disciplinaria enmarcadas en el artículo 29 constitucional.

Para el efecto, se analizarán los instrumentos legales y jurisprudenciales mencionados; los cotejaremos con los esbozados por la Ley Estatutaria de Administración de Justicia; por el Código Disciplinario del Abogado; por la legislación penal y arribaremos a las conclusiones y recomendaciones que permitan viabilizar jurídicamente el derecho a la defensa técnica de los estudiantes de los Consultorios Jurídicos, como defensores de oficio en los procesos disciplinarios.

\section{ANÁLISIS DE LA LEGISLACIÓN Y DE LA JURISPRUDENCIA NACIONALES}

\subsection{Legislación}

El artículo 17 de la Ley 734 de febrero 5 de 2002, con relación al derecho a la defensa, señala:

Durante la actuación disciplinaria el investigado tiene derecho a la defensa material y a la designación de un abogado. Si el procesado ${ }^{5}$ solicita la designación de un defensor asídeberá procederse. Cuando se juzgue como persona ausente deberá estar representado a través de apoderado judicial, si no lo hiciere se designará defensor de oficio, que podrá ser estudiante del

demostrar mucho más que el simple conocimiento de los pormenores de un proceso; $y$, por la otra, el estudiante que represente a un sindicado está también en gran medida representando a su institución académica con todos los compromisos de seriedad, responsabilidad y aptitud que ello acarrea [...]".

5 No se entiende la finalidad con la cual se utilizó este término, el cual es compatible con el Derecho Penal.
Consultorio Jurídico de las universidades reconocidas legalmente ${ }^{6}$.

Por su parte el artículo 93 ídem, con relación al mismo tema, advierte:

Los estudiantes de los Consultorios Jurídicos, podrán actuar como defensores de oficio en los procesos disciplinarios, según los términos previstos en la Ley 583 de $2000{ }^{7}$. Como sujeto procesal, el defensor tiene las mismas facultades del investigado; cuando existan criterios contradictorios prevalecerá el del primero.

Para complementar la disposición anterior, la Ley 583 de junio 12 de 2000 (modificatoria de los artículos 30 y $9^{\circ}$ del Decreto 196 de febrero 12 de 1971, en la época de vigencia, precisó:

Artículo $1^{\circ}$. El artículo 30 del Decreto 196 de 1971 quedará así:

Las facultades de derecho oficialmente reconocidas organizarán, con los alumnos de los dos (2) últimos años lectivos, consultorios jurídicos cuyo funcionamiento requerirá aprobación del respectivo Tribunal Superior de Distrito Judicial, a solicitud de la facultad interesada. Los

6 El día 15 de febrero de 2002, el aparte: "si no lo hiciere se designará defensor de oficio, que podrá ser estudiante del Consultorio Jurídico de las universidades reconocidas legalmente", fue demandado por Carlos Mario Isaza Serrano y la Corte Constitucional mediante Sentencia C-948 de noviembre 6 de 2002 lo declaró exequible, siendo Magistrado Ponente Álvaro Tafur Galvis. Expediente D-3937.

7 El aparte relacionado con: "Los estudiantes de los Consultorios Jurídicos, podrán actuar como defensores de oficio en los procesos disciplinarios, según los términos previstos en la Ley 583 de 2000"fue demandado por Carlos Mario Isaza Serrano y Jesús Cuspoca Ortiz y la Corte Constitucional mediante Sentencia C-1076 de diciembre 5 de 2002 lo declaró exequible, siendo Magistrada ponente Clara Inés Vargas Hernández. Expedientes D-3954 y D-3955. 
consultorios jurídicos funcionarán bajo la dirección de profesores designados al efecto o de los abogados de pobres, a elección de la facultad, y deberán actuar en coordinación con éstos en los lugares en que este servicio se establezca.

Los estudiantes adscritos a los consultorios jurídicos de las facultades de derecho, son abogados de pobres y como tales deberán verificar la capacidad económica de los usuarios. En tal virtud, acompañarán la correspondiente autorización del consultorio jurídico a las respectivas actuaciones judiciales y administrativas.

La prestación del servicio del consultorio jurídico en ningún caso será susceptibles de omisión ni homologación.

Los estudiantes, mientras pertenezcan a dichos consultorios, podrán litigar en causa ajena en los siguientes asuntos, actuando como abogados de pobres:

\section{[...]}

7. De oficio, en los procesos disciplinarios de competencia de las personerías municipales y la Procuraduría General de la Nación ${ }^{8}$.

9. De oficio, en los procesos administrativos de carácter sancionatorio que adelanten las autoridades administrativas, los organismos de control y las entidades constitucionales autónomas ${ }^{9}$.

8 Este numeral fue demandado por Alfredo Castaño Martínez y la Corte Constitucional mediante Sentencia C-143 de febrero 7 de 2001 lo declaró condicionalmente exequible, siendo Magistrado ponente José Gregorio Hernández Galindo. Expediente D-3062, "siempre que los estudiantes que actúen en su desarrollo ejerzan el Derecho bajo la supervisión, la guía y el control de las instituciones educativas a las cuales pertenecen."

9 Este numeral fue demandado por Alfredo Castaño Martínez y la Corte Constitucional mediante Sentencia C-143 de febrero 7 de 2001 lo declaró condicionalmente

\subsection{Jurisprudencia}

La Corte Constitucional, con relación al aparte demandado del artículo 17 de la Ley 734 de febrero 5 de 2002, por intermedio de Carlos Mario Isaza Serrano, mediante Sentencia C-948 de noviembre 6 de 2002, procedió a su declaratoria de exequibilidad, en cuya ponencia Álvaro Tafur Galvis, expresó:

[...]

4.2.5 El análisis de los cargos contra la expresión "que podrá ser estudiante del Consultorio Jurídico de las Universidades reconocidas legalmente" contenida en el artículo 17 de la Ley 734 de 2002.

Para el actor la expresión acusada contenida en el artículo 17 de la ley 734 de $2002^{10}$, en cuanto permite que se designe en los procesos disciplinarios como defensor de oficio a los estudiantes de consultorio jurídico de las universidades reconocidas legalmente, vulnera el derecho a contar con una defensa técnica reconocida en su concepto por el artículo 29 superior 'en todos aquellos casos en que la persona es sometida por medio de un proceso, a las consecuencias de un derecho penal o de corte punitivo'.

Al respecto la Corte recuerda que en varias ocasiones ha tenido oportunidad de pronunciarse sobre la constitucionalidad de las normas que autorizan a los estudiantes

exequible, siendo Magistrado ponente José Gregorio Hernández Galindo. Expediente D-3062, "siempre que los estudiantes que actúen en su desarrollo ejerzan el Derecho bajo la supervisión, la guía y el control de las instituciones educativas a las cuales pertenecen."

10 Artículo 17. Derecho a la defensa. Durante la actuación disciplinaria el investigado tiene derecho a la defensa material y a la designación de un abogado. Si el procesado solicita la designación de un defensor así deberá procederse. Cuando se juzgue como persona ausente deberá estar representado a través de apoderado judicial, si no lo hiciere se designará defensor de oficio, que podrá ser estudiante del Consultorio Jurídico de las universidades reconocidas legalmente. 
de consultorio jurídico de las Universidades reconocidas legalmente para encargarse en determinadas circunstancias de la defensa técnica en los procesos penales, así como para intervenir ante las autoridades judiciales y administrativas.

Así en la Sentencia C-037/96 en la que se examinó la constitucionalidad del artículo 3 de la Ley Estatutaria de administración de justicia relativo al derecho de defensa la Corte expreso lo siguiente:

"Artículo 3". Derecho de defensa. En toda clase de actuaciones judiciales y administrativas se garantiza, sin excepción alguna, el derecho de defensa, de acuerdo con la Constitución Política, los tratados internacionales vigentes ratificados por Colombia y la ley. Los estudiantes de derecho pertenecientes a los consultorios jurídicos de las universidades debidamente reconocidas por el Estado podrán ejercer la defensa técnica con las limitaciones que señale la ley, siempre y cuando la universidad certifique que son idóneos para ejercerla".

\section{Consideraciones de la corte.}

\section{$[\ldots]$}

Comentario especial merece la facultad que el proyecto de ley bajo revisión le otorga a los estudiantes de derecho de las universidades debidamente reconocidas por el Estado para ejercer la defensa técnica, con las limitaciones que establezca la ley, "siempre y cuando la universidad certifique que son idóneos para ejercerla".

\section{(...)}

Finalmente, la Corte estima que la certificación de idoneidad que las universidades deban otorgar a los estudiantes de derecho de los consultorios jurídicos para ejercer la defensa técnica, no puede de ningún modo circunscribirse exclusivamente a la valoración académica de la persona, sino que debe incluir el comportamiento moral y ético que el estudiante ha demostrado a lo largo de sus carrera universitaria. Lo anterior porque, de una parte, la jurisprudencia de esta Corte ha sido clara en resaltar que quien asista a una persona en su defensa judicial debe demostrar mucho más que el simple conocimiento de los pormenores de un proceso; $y$, por la otra, el estudiante que represente a un sindicado está también en gran medida representando a su institución académica con todos los compromisos de seriedad, responsabilidad y aptitud que ello acarrea.

En estos términos, entonces, el artículo $3^{\circ}$ será declarado exequible" ${ }^{11}$.

Así mismo en relación con el examen de constitucionalidad de algunos artículos del Decreto 196 de 1971 "Por el cual se dicta el estatuto del ejercicio de la Abogacía", la Corte señaló sobre este tema lo siguiente:

7. Así pues, "en asuntos penales es requisito indispensable que quien obre en representación del sindicado, esto es, quien deba asumir su defensa, ha de ser u profesional del derecho, es decir, aquella persona que ha optado al título de abogado y, por consiguiente, tiene los conocimientos jurídicos suficientes para ejercer una defensa técnica, especializada y eficaz, en aras a garantizar al procesado su derecho de defensa"12.

8. Sin embargo, ha de tenerse en cuenta que en la práctica es difícil que siempre se cuente con profesionales del derecho $y$, por tanto, solamente para los casos excepcionales en que ello ocurra, la ley

11 Cfr. Corte Constitucional .Sentencia C-037/96 M.P. Vladimiro Naranjo Mesa.

12 Cfr. Corte Constitucional. Sala Plena. Sentencia N ${ }^{\circ}$ C-071 de 1995. M.P. Dr. Carlos Gaviria Díaz. 
"puede habilitar defensores que reúnan al menos las condiciones de egresados, o de estudiantes de derecho pertenecientes a un consultorio jurídico, (Decreto 196 de 1971, arts. 30, 31 y 32, Decreto 765 de 1977) pues de esta forma se consigue el objetivo de que dichos defensores sean personas con cierta formación jurídica"13" 14.

De dichos pronunciamientos se desprende que esta Corporación ha considerado que, salvo en el caso de los procesos penales en los que solamente de manera excepcional cabe acudir como defensores de oficio a los estudiantes de las universidades reconocidas legalmente, éstos pueden asumir la defensa en todo tipo de procesos ${ }^{15}$, sin que ello signifique la vulneración del derecho de defensa señalado en el artículo 29 superior. No sobra precisar al respecto, por lo demás, que la exigencia constitucional de defensa técnica ha sido circunscrita por el Constituyente al proceso penal y no se ha extendido a otro tipo de procesos ${ }^{16}$.

13 Cfr. Corte Constitucional. Sala Plena. Sentencia $N^{\circ}$ SU-044 de 1995. M.P. Dr. Antonio Barrera Carbonell.

Cfr. Sentencia C-025/98 M.P Fabio Morón Díaz.

15 Cfr. Sentencia C-037/96 M.P. Vladimiro Naranjo Mesa.

16 Ver sentencia C-131/02 M.P. Jaime Córdoba Triviño. En esta sentencia de febrero 2 de 2002, cuya demanda presentara Ana Lucía Padrón Carvajal, Expediente D-3674, allí se dijo: 7. El artículo 29 constitucional consagra el derecho fundamental al debido proceso. En el inciso primero establece una cláusula general que extiende la cobertura de ese derecho a toda clase de actuaciones judiciales y administrativas y en virtud de ella ningún ámbito de solución de controversias y de aplicación del derecho sustancial está sustraído de la obligación de observar estrictamente ese derecho fundamental. Y en los incisos dos a cinco consagra una serie de principios que desarrollan el derecho fundamental al debido proceso entre los que se encuentran los principios de legalidad, juez natural, favorabilidad, presunción de inocencia, derecho a la defensa, derecho a la defensa técnica, a un proceso sin dilaciones injustificadas, a aportar y contradecir pruebas, a la impugnación de la sentencia condenatoria, a no ser juzgado dos veces por el mismo hecho y a la nulidad de la prueba obtenida con violación del debido proceso. Tomada de MEJÍA OSSMAN, Jaime y MEJÍA ACOSTA, Karolina. Temática Jurisprudencial
Ahora bien, la Corte llama la atención sobre el hecho de que la norma a la que pertenece la expresión acusada, alude solamente al caso en que se juzgue disciplinariamente como persona ausente a un procesado, a quien, si no actúa a través de apoderado judicial-posibilidad que le señala claramente la norma-, se le designará defensor de oficio que podrá ser estudiante del consultorio jurídico de las universidades reconocidas legalmente.

Estas circunstancias, unidas al hecho de que como se ha señalado reiteradamente en esta providencia las garantías del debido proceso predicables en el ámbito disciplinario deben entenderse moduladas en función de los objetivos propios de la actuación disciplinaria y que la situación en la que se autoriza la intervención de los estudiantes de consultorio jurídico denota, salvo existencia de fuerza mayor o caso fortuito, un incumplimiento de los deberes del procesado en relación con su comparecencia al proceso disciplinario, llevan a la Corte a concluir que la expresión acusada no vulnera el artículo 29 superior.

Así las cosas la Corte declarará la exequibilidad de la expresión "que podrá ser estudiante del Consultorio Jurídico de las Universidades reconocidas legalmente" contenida en el artículo 17 de la Ley 734 de 2002 y así lo señalará en la parte resolutiva de esta sentencia. [...]".

del Proceso Disciplinario. Bogotá. Editorial Ediciones Doctrina y Ley. 2009.

(...)

De lo expuesto se deduce, entonces, que la exigencia constitucional de defensa técnica ha sido circunscrita por el constituyente al proceso penal y no se ha extendido a otro tipo de procesos como es el caso del proceso de responsabilidad fiscal. De allí que la sola invocación de la referencia constitucional al derecho a la defensa técnica contenida en el artículo 29 de la Carta no baste para acreditar la inexequibilidad de una norma que le ha asignado carácter facultativo al derecho a la defensa técnica en la diligencia de exposición libre y espontánea que se rinde en el proceso de responsabilidad fiscal. ...". 
De la misma manera la Corte Constitucional, con relación al aparte demandado del artículo 93 de la Ley 734 de febrero 5 de 2002, por intermedio de Carlos Mario Isaza Serrano y Jesús Cuspoca Ortiz, mediante Sentencia C-1076 de diciembre 5 de 2002, procedió a su declaratoria de exequibilidad, en cuya ponencia Clara Inés Vargas Hernández, dijo:

\section{[...] 15. Artículo 93, parcial.}

Artículo 93. Estudiantes de consultorios jurídicos y facultades del defensor. Los estudiantes de los Consultorios Jurídicos, podrán actuar como defensores de oficio en los procesos disciplinarios, según los términos previstos en la Ley 583 de 2000. Como sujeto procesal, el defensor tiene las mismas facultades del investigado; cuando existan criterios contradictorios prevalecerá el del primero.

\section{a. Cargos de la demanda.}

El actor sostiene que es contrario a los artículos 29 inciso $2^{\circ}, 123$ inciso final y 150 numeral 23 de la Carta, la parte del precepto demandado que permite que los estudiantes de consultorio jurídico actúen como defensores de oficio en los procesos disciplinarios, por cuanto en los procesos en los cuales existe una represión estatal formalizada, la defensa del procesado no puede ser adelantada por una persona que no se encuentre científica y técnicamente habilitada como profesional del derecho.

\section{$[\ldots]$}

e. Consideraciones de la Corte.

No comparte la Corte las aseveraciones del actor en el sentido de señalar que la defensa que realiza un estudiante de consultorio jurídico en procesos disciplinarios atente contra el derecho a contar con una defensa técnica. En efecto, esta Corporación ha insistido en que las defensas que realizan los estudiantes de derecho durante su consultorio jurídico, además de constituir una valiosa labor social, lejos de vulnerar el derecho a un debido proceso, en especial a contar con una adecuada defensa técnica, lo garantizan.

En relación con el debido proceso, el artículo 29 de la Carta Política establece que "quien sea sindicado tiene derecho a la defensa y a la asistencia de un abogado escogido por él, o de oficio, durante la investigación y el juzgamiento". Como lo ha definido la Corte, este precepto superior exige que en asuntos penales es requisito indispensable que quien asuma la defensa o representación de un sindicado debe ser una persona que ha obtenido el título de abogado, suponiéndose que tiene los suficientes conocimientos jurídicos para adelantar una defensa técnica, especializada y eficaz, con el fin de asegurar al procesado su derecho de defensa ${ }^{17}$.

No obstante, este principio general no tiene carácter absoluto. La Corte ha aceptado, de manera excepcional, que en materia penal se pueda habilitar defensores que al menos reúnan las condiciones de egresados o estudiantes de derecho que pertenezcan a un consultorio jurídico, en razón de que no puede desconocerse el hecho de que en algunos municipios no puede contarse con la presencia de un abogado titulado para que ejerza la labor de defensor de oficio en tales asuntos, lo que igualmente le causaría perjuicio a los procesados. Así en Sentencia SU-044 de 1995, M.P. Antonio Barrera Carbonell, la Corte ya había expresado que:

"La ley no puede autorizar a cualquier persona para intervenir en la defensa

17 Cfr. Sentencias C-592 de 1993; SU-o44 de 1995; C-071 de 1995; C-037, C-049 y C-069 de 1996; 025 de 1998, C-143 de 2001 
de un sindicado; solamente en casos excepcionales en que no pueda contarse con abogado titulado puede habilitar defensores que reúnan al menos las condiciones de egresados, o estudiantes de derecho pertenecientes a un consultorio jurídico, (Decreto 176/91, arts. 30, 31, y 32, Decreto 765/77) pues de esta forma se consigue el objetivo de que dichos defensores sean personas con cierta formación jurídica".

Posteriormente, en Sentencia C-071 de 1995, la Corte expresó al respecto lo siguiente:

"En asuntos penales es requisito indispensable que quien obre en representación del sindicado, esto es, quien deba asumir su defensa, ha de ser un profesional del derecho, es decir, aquella persona que ha optado al título de abogado $y$, por consiguiente, tiene los conocimientos jurídicos suficientes para ejercer una defensa técnica, especializada y eficaz, en aras de garantizar al procesado su derecho de defensa. Sin embargo, la Corte no puede desconocer que existen municipios en donde no es posible contar con abogados titulados para que cumplan la labor de defensor de oficio en asuntos penales, lo que causa perjuicio a los procesados, y es por ello que en sentencia SU-044/95, con ponencia del Magistrado Antonio Barrera Carbonell, aceptó que en casos excepcionalísimos, se puedan habilitar defensores que reúnan al menos las condiciones de egresados, o estudiantes de derecho pertenecientes a un consultorio jurídico".

Al revisar el artículo $3^{\circ}$ del proyecto de Ley Estatutaria de la Administración de Justicia, que consagra la garantía del derecho de defensa en toda clase de actuaciones judiciales y administrativas, sin excepción alguna, y faculta a los estudiantes de derecho pertenecientes a los consultorios jurídicos de las universidades debidamente reconocidas por el Estado para ejercer la defensa técnica con las limitaciones que señale la ley siempre $y$ cuando la universidad certifique que son idóneos para ejercerla, la Corte, aunque reiteró la necesidad de que tal defensa sea asumida por un abogado titulado, encontró exequible esta facultad recalcando lo que al respecto ya se había considerado en Sentencias C-592 de 1993, y C-071 de 1995, y expresando además que "sólo ante la inexistencia de abogados titulados en algún municipio del país o ante la imposibilidad física y material de contar con su presencia, los estudiantes de los consultorios jurídicos pueden hacer parte de un proceso penal", y agregando que "la certificación de idoneidad que las universidades deban otorgar a los estudiantes de derecho de los consultorios jurídicos para ejercer la defensa técnica, no puede de ningún modo circunscribirse exclusivamente a la valoración académica de la persona, sino que debe incluir el comportamiento moral y ético que el estudiante ha demostrado a lo largo de su carrera universitaria".

En la Sentencia C-617 de 1996, que declaró exequible, en los términos de la misma, el literal a) del artículo $30 \mathrm{del}$ Decreto 196 de 1971 -Estatuto de la Abogacía-, los cargos que analizó la Corte versaban sobre la presunta infracción al artículo 29 Fundamental, pues en criterio del actor la disposición acusada faculta a los estudiantes en forma absoluta y sin límite en el tiempo para ejercer funciones jurídicas, desconociendo que el citado precepto superior consagra el derecho a la defensa técnica, en virtud de la cual la defensa de los sindicados solo puede ser adelantada por profesionales en derecho y solo excepcionalmente por estudiantes en caso de ausencia del abogado.

Frente a esta acusación, la Corte en la mencionada providencia se refirió a la 
necesidad de garantizar a los procesados el derecho fundamental a la defensa técnica por parte de personas con idoneidad personal y profesional, reiterando que sólo ante la inexistencia de abogados titulados $o$ ante la imposibilidad física y material de contar con su presencia dicha defensa puede ser ejercida en asuntos penales por estudiantes orientados por las facultades de derecho. Al respecto la Corte consideró:

"En realidad, aunque a los alumnos de los últimos años de Derecho no se les puede catalogar como expertos en materia penal, pues por su mismo estado carecen de la trayectoria que se supone exhiben los abogados que han obtenido el título -sin que esto último constituya tampoco verdad universal ni probada-, las posibilidades de defensa técnica que ofrecen son mucho mejores que las de profesionales en otras actividades o las del ciudadano honesto al que aludía una norma legal declarada inexequible por esta Corte (Sentencia C-049 del 8 de febrero de 1996. M.P.: Dr. Fabio Morón Díaz).

"La normatividad objeto de análisis tiene precisamente el sentido de asegurar que la garantía constitucional de la defensa no sea frustrada por la fuerza de las circunstancias, apelando al concurso de quienes están próximos a cumplir los requisitos necesarios para optar el título y tienen conocidos los fundamentos básicos de índole sustancial y procesal, indispensables para asumir la representación judicial de personas económicamente débiles".

De tal suerte que, recurriendo a un argumento ad maiori ad minus, la Corte considera que si en materia penal es constitucionalmente válido que los estudiantes de consultorio jurídico atienda determinadas causas, con mayor razón en materia disciplinaria, como quiera que las sanciones a imponer son de menor entidad y afectación de las libertades públicas.
Por las anteriores razones, la Corte declarará exequible la expresión estudiantes de consultorios jurídicos, así como la expresión Los estudiantes de los Consultorios Jurídicos, podrán actuar como defensores de oficio en los procesos disciplinarios, según los términos previstos en la Ley 583 de 2000, previstas en el artículo 93 de la Ley 374 de 2002, por los cargos analizados en esta sentencia. [...]".

\section{EL CÓDIGO DISCIPLINARIO DEL ABOGADO, EL DERECHO PENAL Y EL "DEFENSOR DE OFICIO"}

En forma posterior a la expedición de la Ley 583 de junio 12 de 2000 y de los artículos 17 y 93 de la Ley 734 de febrero 5 de 2002, así como de las Sentencias C-131 de febrero 2 de 2002, C-948 de noviembre 6 de 2002 y C-1076 de diciembre 5 de 2002, el Congreso de Colombia, mediante la Ley 1123 de enero 22 de 2007, expidió el Código Disciplinario del Abogado, en donde en los artículos 12, 28 (21) y 34 (i), señaló:

Artículo 12. Derecho a la defensa. Durante la actuación el disciplinable tiene derecho a la defensa material y a la designación de un abogado. Cuando se juzgue como persona ausente se designará defensor de oficio.

Artículo 28. Deberes profesionales del abogado. Son deberes del abogado:

21. Aceptar y desempeñar las designaciones como defensor de oficio. Sólo podrá excusarse por enfermedad grave, incompatibilidad de intereses, ser servidor público, o tener a su cargo tres (3) o más defensas de oficio, o que exista una razón que a juicio del funcionario de conocimiento pueda incidir negativamente en la defensa del imputado o resultar violatoria de los derechos fundamentales de la persona designada.

Artículo 34. Constituyen faltas de lealtad con el cliente: 
i. Aceptar cualquier encargo profesional para el cual no se encuentre capacitado, o que no pueda atender diligentemente en razón del exceso de compromisos profesionales.

\section{[...]. ${ }^{18}$}

De los textos legales y de las sentencias pronunciadas por la Corte Constitucional, antes de la expedición de la Ley 1123 de enero 22 de 2007, se puede concluir que la figura del defensor de oficio, en cabeza de los estudiantes de los consultorios jurídicos de las universidades reconocidas legalmente, era viable en materia penal, con sus respectivas limitaciones, $y$, en materia disciplinaria, sin limitación alguna, por cuanto el derecho a la defensa técnica solamente operaba, como obligatoria, en los procesos penales y no en ninguna otra clase de procesos.

En la actualidad con la Constitución Política de Estado Social de Derecho; con el advenimiento de la Ley 1123 de enero 22 de 2007 y con los estudios que se han desarrollado en el tema del derecho disciplinario, en torno a los derechos fundamentales del investigado ${ }^{19}$, no es posible admitir esa interpretación flexible en detrimento de la defensa técnica en el campo del derecho disciplinario, toda vez que la misma atenta contra

18 Se debe tener en cuenta que esta ley (1123 de enero 22 de 2007), derogó al Decreto 196 de febrero 12 de 1971 y en especial su artículo 30, que fuera modificado por la Ley 583 de junio 12 de 2000, quedando sin respaldo el litigio en causa ajena de los estudiantes de los consultorios jurídicos de las universidades reconocidas legalmente, ya que el Código Disciplinario del Abogado no se ocupó del tema.

19 Ver: BARRETO ARDILA, Hernando. "Principios y Normas Rectoras de la Ley Disciplinaria”. Bogotá. Imprenta Nacional de Colombia. 1999. MEJÍA OSSMAN, Jaime. "Principios Constitucionales y Legales de la Ley Disciplinaria para las Fuerzas Militares de Colombia. Bogotá. Ediciones Doctrina y Ley. 2006. MEJÍA OSSMAN, Jaime. "Conferencias de clase para la Especialización en Derecho Sancionatorio de la Universidad Militar Nueva Granada. Bogotá. 2007 y FORERO, José Rory. "Principiosy Garantías Constitucionales en el Ámbito Disciplinario de los Servidores Estatales". Ediciones Nueva Jurídica. 2003. la dignidad humana, ya que el artículo 29 de la Carta Fundamental, no permite hacer distinción alguna entre lo penal y lo administrativo, para la aplicación del debido proceso, máxime cuando el encabezamiento de la norma constitucional precisa que "el debido proceso se aplicará a toda clase de actuaciones judiciales y administrativas" y ello es suficiente para advertir que el constituyente no diferenció entre lo uno y lo otro. Darle paso a la interpretación de que el debido proceso, en torno a la defensa técnica, solamente es obligatorio en el terreno del derecho penal, es desintegrar o atomizar la norma constitucional y aislarla de su contexto armonioso y organizado, solamente porque el inciso $4^{\circ}$ del artículo 29 de la Ley de Leyes se refiere a "quien sea sindicado". Tan desafortunada posición, permitiría que en el día de mañana se aplicara, "obligatoriamente", el principio de favorabilidad únicamente en materia penal, porque así lo dice el inciso $3^{\circ}$ del artículo 29 ídem o se excluyeran los procesos, distintos del penal, de la aplicación "obligatoria" de los principios de celeridad, de contradicción y non bis in ídem, o que se autorizaran algunas limitaciones a la solicitud, práctica y controversia de pruebas, dizque porque el inciso $4^{\circ}$ del artículo 29 ibídem, opera "obligatoriamente" para el "sindicado", en la misma forma como para la defensa técnica.

Por lo tanto el argumento "ad maiori ad minus" de la Corte Constitucional, expresado por Clara Inés Vargas Hernández, en el sentido "que si en materia penal es constitucionalmente válido que los estudiantes de consultorio jurídico atiendan determinadas causas, con mayor razón en materia disciplinaria, como quiera que las sanciones a imponer son de menor entidad y afectación de las libertades públicas", no es coherente con la Carta Política, toda vez que esa posición afecta el derecho fundamental a la defensa, porque las sanciones disciplinarias sí son de mayor entidad y afectan en mayor grado las libertades públicas (destitución e inhabilidad de 10 a 20 años o destitución e inhabilidad permanente si se causa detrimento patrimonial al Estado), razón por la cual el investigado o disciplinado debe gozar de una especializada defensa técnica, la cual no es posible obtener con los estudiantes pertenecientes 
a los consultorios jurídicos de las Universidades reconocidas legalmente, máxime cuando las universidades, en su inmensa mayoría no tienen establecida la cátedra de Derecho Disciplinario como materia básica. Igualmente debe advertirse que las consecuencias de un proceso disciplinario, si este llega a una sanción, son gravísimas en la vida de proyección laboral, social, sicológica, personal y familiar del sancionado $y$, que el hecho de que sea válido constitucionalmente que en materia penal los estudiantes de los Consultorios Jurídicos lo pueden hacer, no es menos cierto que en materia penal no pueden actuar en asuntos ante los Jueces Penales del Circuito, ni ante los Tribunales, ni ante las Altas Cortes, y en cambio en materia disciplinaria no existe limitación alguna, lo cual es abiertamente desproporcionado e inequitativo.

\section{CONCLUSIONES}

Resulta de gran importancia expresar que al desaparecer, en materia penal, la participación de los defensores de oficio conformados por los estudiantes de los consultorios jurídicos de las universidades legalmente reconocidas, por haberse derogado el artículo 131 de la Ley 600 de julio 24 de 2000 o Código de Procedimiento Penal, técnicamente esa función tendrá que asignarla el Sistema Nacional de Defensoría Pública (artículo 118 de la Ley 906 de agosto 31 de 2004), la cual recaerá en abogados titulados y especializados en el tema. Recuérdese que en la Sentencia C-040 de enero 28 de 2003, por demanda que presentara Juan Carlos Gallego Chávez (expediente D-4165), la Corte Constitucional con ponencia de Clara Inés Vargas Hernández, declaró exequible el inciso $2^{\circ}$ del artículo 131 del Código de Procedimiento Penal anterior, "en el entendido que la facultad allí consagrada la pueden ejercer los estudiantes de derecho adscritos a los consultorios jurídicos siempre y cuando en el lugar correspondiente no existan abogados titulados o temporalmente habilitados según la ley, o ante la imposibilidad física y material de contar con su presencia o la de un defensor público y que acrediten idoneidad mediante certificación expedida por la universidad correspondiente", lo cual, para efectos de nuestro tema, recobra muchísima importancia, como precedente constitucional, ya que, en materia disciplinaria, como se ha venido expresando y por respeto al debido proceso constitucional, el derecho a la defensa tendrá que cumplir con las exigencias señaladas en materia penal, máxime que el artículo 34, literal (i) de la Ley 1123 de enero 22 de 2007, señaló como falta contra la lealtad, en su catálogo de tipicidades: "(i). Aceptar cualquier encargo profesional para el cual no se encuentre capacitado [...]". Luego los estudiantes de los consultorios jurídicos de las universidades legalmente reconocidas, únicamente podrán ejercer la función oficiosa, previa acreditación de su "idoneidad" mediante una certificación expedida por la universidad correspondiente, en la cual se constate además que estuvieron bajo el "control" y "supervisión" de la Universidad.

Solo de esa manera se podrá garantizar el derecho a la defensa material, en el evento de que se requiera el nombramiento oficioso para la representación de la persona ausente. Además, así se evitará incurrir en la afectación de los deberes del abogado enmarcados en el numeral 21 del artículo 28 de la Ley 1123 de enero 22 de 2007, ya que el defensor de oficio tiene la obligación de manifestarle al juez disciplinario que su falta de conocimiento puede incidir negativamente en la defensa del disciplinado o que la misma podría resultar violatoria de sus derechos fundamentales, para que él lo pueda excusar.

Debe hacerse constar que como profesor universitario aprecio mucho que la ley permita la práctica a los estudiantes de las facultades de derecho que pertenecen a los Consultorios Jurídicos, pero debo confesar con absoluta franqueza que ellos no son los más llamados a dirigir la defensa técnica de los disciplinados, toda vez que las Universidades aún no los ha preparado en esa subespecialidad del Derecho Sancionatorio que lo constituye el Derecho Disciplinario; subespecialidad muy exigente, que 
además comporta una serie de conocimientos en las áreas constitucional, penal, administrativa, disciplinaria, probatoria, de derechos humanos $y$ de derecho internacional humanitario. Por lo anterior creemos que la defensa técnica ejercida por los estudiantes de los Consultorios Jurídicos, no sería una garantía al mandato constitucional del artículo 29, y por ende con la intervención de los mismos, se le disminuiría la defensa a quienes estén soportando la investigación o la acusación disciplinaria, salvo, como se ha venido insistiendo, que la universidad, bajo su responsabilidad, no solamente les certifique su "idoneidad", sino que los "supervisen", los "guíen" y "controlen" en tan compleja disciplina, tal como lo expresó la Corte Constitucional en la Sentencia C-143 de febrero 7 de 2001, en la cual condicionó con esas precisiones a los numerales $7^{\circ}$ y $9^{\circ} \mathrm{del}$ artículo $1^{\circ}$ de la Ley 583 de junio 12 de 2000 (modificatoria del artículo 30 del Decreto 196 de febrero 12 de 1971) ${ }^{20}$.

Además, debe dejarse muy en claro que el artículo $3^{\circ}$ de la Ley Estatutaria de la Administración de Justicia (Ley 270 de marzo 7 de 1996), al señalar que "en toda clase de actuaciones judiciales y administrativas se garantiza, sin excepción alguna, el derecho de defensa, de acuerdo con la Constitución Política, los tratados internacionales vigentes ratificados por Colombia y la ley; que los estudiantes de derecho pertenecientes a los consultorios jurídicos de las universidades debidamente reconocidas por el Estado podrán ejercer la defensa técnica con las limitaciones que señale la ley, siempre y cuando la universidad certifique que son idóneos para ejercerla", nos está permitiendo hacer la interpretación que venimos

20 En esos numerales $\left(7^{\circ}\right.$ y $\left.9^{\circ}\right)$, la Corte Constitucional, por demanda que presentara Alfredo Castaño Martínez, mediante Sentencia C-143 de febrero 7 de 2001 los declaró condicionalmente exequible, siendo Magistrado ponente José Gregorio Hernández Galindo. Expediente D-3062, "siempre que los estudiantes que actúen en su desarrollo ejerzan el Derecho bajo la supervisión, la guía y el control de las instituciones educativas a las cuales pertenecen." haciendo, en razón de que la Ley 1123 de enero 22 de 2007 efectivamente establece una limitación a los estudiantes de derecho pertenecientes a los consultorios jurídicos de las universidades debidamente reconocidas por el Estado, para que en las "actuaciones administrativas", como es el caso del proceso disciplinario, se nombren estudiantes "capacitados" para desempeñarse como defensores de oficio, "idoneidad" que tendrá que "certificar" la respectiva universidad, una vez se constate la falta de abogados titulados o temporalmente habilitados por la ley y se pruebe la imposibilidad física y material de contar con su presencia o la de un defensor público, de común acuerdo con la Sentencia C-040 de enero 28 de 2003, que para estos efectos habrá de considerarse precedente Constitucional.

De todas maneras dejamos la inquietud para que el nuevo señor Procurador General de la Nación (Dr. Alejandro Ordoñez Maldonado), a través de una directiva y en cumplimiento de las funciones que le asigna el artículo $7^{\circ}$, numeral $7^{\circ}$ del Decreto 262 de febrero 22 de 2000, establezca criterios con los cuales los jueces disciplinarios ${ }^{21}$ deben interpretar y aplicar este principio fundamentador del derecho a la defensa, ya que es claro que la entrada en vigencia de la Ley 1123 de enero 22 de 2007, generó algunas preocupaciones que aplican, en igualdad de condiciones, tanto en el campo penal como en el campo disciplinario, lo cual resulta robustecido con el artículo 29 de la Constitución Política, el artículo $3^{\circ}$ de la Ley 270 de marzo 7 de 1996 (Ley Estatutaria de la Administración de Justicia y la Sentencia C-037 de

21 Así lo vienen llamando las Sentencias T-412 de mayo 22 de 2004. Demandante Sandra Mora Moncaleano, Magistrado sustanciador Rodrigo Escobar Gil. Expediente T-1266441; T-1093 de noviembre 4 de 2004. Demandante Gerardo Ramón de los Rios Chavarriaga y otros. Magistrado ponente Manuel José Cepeda Espinosa. Expediente T-791349; C-720 de agosto 23 de 2006. Demandante Sandra Vanegas Leaño. Magistrada ponente Clara Inés Vargas Hernández. Expediente D-5968 y C-987 de noviembre 29 de 2006. Demandante Sandra Mónica Cardozo Rojas. Magistrado ponente Nilson Pinilla Pinilla. Expediente D-6273. 
febrero 5 de 1996, que declaró su exequibilidad y el Código Disciplinario del Abogado.

Por ahora seguiremos insistiendo en que la intervención de los estudiantes de los consultorios jurídicos de las universidades reconocidas legalmente, como defensores de oficio en los procesos disciplinarios, vulnera los derechos fundamentales del disciplinado, cuando ellos son nombrados sin tener la capacidad académica y sin que la universidad certifique su idoneidad, amén que también se de fe de la moralidad reclamada por la Corte Constitucional; que los mismos se encuentren bajo el control y supervisión del especialista en el tema en el respectivo Consultorio Jurídico y una vez se constate la falta de abogados titulados o temporalmente habilitados por la ley y se pruebe la imposibilidad física y material de contar con su presencia o la de un defensor público, de común acuerdo con la Sentencia C-040 de enero 28 de 2003, que para estos efectos, como ya lo manifesté, habrá de considerarse precedente Constitucional, pues el derecho a la defensa técnica, en materia disciplinaria, no puede ser objeto de "matizaciones", "flexibilizaciones", "morigeraciones", "modulaciones" o "minimizaciones" y de interpretación y aplicación con "menor rigurosidad" que en materia penal, toda vez que ese derecho fundamentador debe aplicarse por igual en cualquier materia que comprenda el derecho sancionador o punitivo del Estado.

\section{BIBLIOGRAFÍA}

BARRETOARDILA, Hernando. (1999). "Principios y Normas Rectoras de la Ley Disciplinaria”. Bogotá. Imprenta Nacional de Colombia.

MEJÍA OSSMAN, Jaime. (2003). Código Disciplinario Único. Primera Edición. Bogotá. Ediciones Doctrina y Ley.

MEJÍA OSSMAN, Jaime. (2006). Principios Constitucionales y Legales de la Ley Disciplinaria para las Fuerzas Militares de Colombia. Primera Edición. Bogotá. Doctrina y Ley.

MEJÍA OSSMAN, Jaime. (2007). Régimen Disciplinario. Primera Edición. Bogotá. Doctrina y Ley.

MEJÍA OSSMAN, Jaime y MEJÍA ACOSTA, Karolina. (2009). Temática Jurisprudencial del Proceso Disciplinario. Primera Edición. Bogotá. Doctrina y Ley.

FORERO, José Rory. (2003). Principios y Garantías Constitucionales en el Ámbito de los Servidores Estatales. Primera Edición. Bogotá. Ediciones Nueva Jurídica.

Corte Constitucional. Sentencias de Exequibilidad. Bogotá. (Leyes 200/95, 734/02 y 836/03) a partir del año 1995 a la fecha. 